\title{
PENGARUH PADAT TEBAR YANG BERBEDA TERHADAP KELANGSUNGAN HIDUP DAN PERTUMBUHAN BANGGAI CARDINAL FISH (BCF) (Pteropogon kaurdeni) DALAM WADAH TERKONTROL
}

\section{THE EFFECT OF DIFFERENT STOCKING DENSITY ON SURVIVAL AND GROWTH OF CARDINAL FISH (BCF) (Pteropogon kaurdeni) IN CONTROLLED TANK}

\author{
Ari Andayani ${ }^{1)}$, Baiq Hilda Astriana ${ }^{1)}$, Nurliah ${ }^{1 *}$ \\ ${ }^{1)}$ Program Studi Budidaya Perairan Fakultas Pertanian, Universitas Mataram \\ Jl. Pendidikan No, 37 Mataram, NTB
}

\begin{abstract}
Abstrak
Tujuan penelitian adalah untuk mengetahui pengaruh padat tebar yang berbeda terhadap kelangsungan hidup dan pertumbuhan Banggai Cardinal Fish $(B C F)$ (Pteropogon kaurdeni) pada wadah terkontrol. Penelitian menggunakan metode ekperimental dengan rancangan acak lengkap yang terdiri dari tiga perlakuan kepadatan yaitu perlakuan A 0,833 ekor/l, perlakuan B 1,667 ekor/l, dan perlakuan C 2,5 ekor/l dan masing-masing perlakuan diulang sebanyak empat kali ulangan. Hasil penelitian meunujukkan bahwa padat tebar yang berbeda berpengaruh signifikan pada tingkat kelangsungan hidup dan laju pertumbuhhan harian ikan $B C F$, akan tetapi tidak berpengaruh terhadap pertumbuhan panjang mutlak dan berat mutlak ikan $B C F$. Tingkat kelangsungan hidup ikan $B C F$ yang lebih baik terdapat pada perlakuan A dan B dengan kepadatan 0,833 ekor/l dan 1,667 ekor/l sebesar 80\% dan $78 \%$, senentara itu laju pertumbuhan berat harian tertinggi ikan $B C F$ terdapat pada perlakuan B dengan kepadatan 1,667 ekor/l sebesar 0,689\%.
\end{abstract}

Kata kunci : Kelangsungan hidup, pertumbuhan, Pteropogon kaurdeni

\begin{abstract}
Research objective was to determine the effect of different stocking densities on survival and growth of Banggai Cardinal Fish (BCF) (Pteropogon kaurdeni) in controlled containers. The study used an experimental method with a completely randomized design consisting of three treatment densities namely treatment A 0.833 ind / 1, treatment B 1.667 ind / 1, and treatment C 2.5 ind / 1. Each treatment was repeated four times. The result shows that the different stocking densities effect significantly to the survival rate and daily growth rate of $\mathrm{BCF}$, but do not effect significantly to the growth and length gain of BCF. The survival rate of BCF in treatment A gives the highest result $(80 \%)$ and be followed by treatment $\mathrm{B}(78 \%)$ and treatment $\mathrm{C}(54 \%)$. In addition, the highest daily growth rate of BCF is found in treatment B $(0,689 \%)$ and this is followed by treatment $\mathrm{C}(0,614 \%)$ and $\mathrm{A}(0,608 \%)$. .
\end{abstract}

Keywords : Survival, Growth, Pteropogon kaurdeni

\section{Pendahuluan}

Ikan Banggai Cardinal Fish (BCF) $P$. kaurdeni masuk dalam kategori red list dan dikategorikan sebagai spesies yang terancam punah oleh IUCN (Vagelli, 2008). Selain itu, beberapa pihak mencoba untuk memasukkan $B C F$ ke dalam daftar Appendix II The Convention on International Trade of Endangered Spesies of Fauna and Flora (CITES) sehingga perdagangan ikan $B C F$ hanya boleh dilakukan dari hasil budidaya (Ndobe, 2011).

email korespondensi :

nurliah.buhari@unram.ac.id
Secara ekologis, ikan $B C F$ dapat berfungsi sebagai parameter degradasi mikrohabitatnya seperti terumbu karang dan bulu babi. Secara ekonomi, ikan $B C F$ juga dapat dimanfaatkan untuk meningkatkan pendapatan masyarakat. Keberadaan ikan $B C F$ di alam menarik minat wisatawan domestik maupun mancanegara. Selain itu, harga ikan $B C F$ cukup baik di tingkat nelayan yaitu berkisar Rp1.500/ekor - Rp5.000/ekor sedangkan harga ekspor bisa mencapai US\$2,5/ekor - US\$22/ekor (Ndobe, et al, 2013 ). 
Berdasarkan kondisi tersebut maka sudah seharusnya dilakukan upaya pelestarian. Salah satu solusi atau upaya yang dapat dilakukan dalam memenuhi permintaan pasar yaitu melalui kegiatan budidaya. Upaya kegiatan budidaya $B C F$ telah dilakukan dan telah berhasil dipijahkan, antara lain di Balai Budidaya Laut (BBL) Ambon, Balai Besar Riset Perikanan Budidaya Laut (BBRPBL) Gondol Bali dan Balai Perikanan Budidaya Laut (BPBL) Sekotong, Lombok Barat, Nusa Tenggara Barat. Pemeliharaan dilakukan pada keramba jaring apung (KJA) dengan diberi bulu babi (Diadema sitosum) sebagai tempat berlindung. Akan tetapi, kegiataan budidaya $B C F$ pada KJA memiliki kendala seperti sulitnya akses untuk memberi pakan karena terkadang adanya ombak atau gelombang serta cuaca di laut yang tak menentu. Dan untuk mempermudahnya dapat dilakukan dengan budidaya pada wadah terkontrol di akuarium agar memudahkan pembudidaya atau teknisi dalam memelihara ikan $B C F$.

Dalam kegiatan pemeliharaan ikan $B C F$ secara terkontrol juga perlu diketahui jumlah padat tebar yang baik dan tepat untuk memicu kelangsungan hidup dan pertumbuhan ikan $B C F$. Menurut Diatin, et al. (2014), kepadatan merupakan faktor terpenting dalam budidaya ikan terutama pada budidaya intensif yang menghasilkan produksi ikan tinggi.

Salah satu upaya yang potensial adalah pengembangan budidaya Pterapogon kauderni in-situ, yaitu pada lingkungan alami atau habitat aslinya. Menurut Sugama (2008), usaha yang dapat dilakukan untuk menghindari kepunahan populasi di alam dan sediaan untuk penggemar akuarium adalah dengan cara membenihkan secara terkontrol. Di Indonesia belum pernah dilaporkan keberhasilan membenihkan ikan $B C F$ secara terkontrol, laporan yang ada umumnya menginformasikan sumber daya ikan $B C F$ di Kepulauan Banggai dan perbaikan teknik penangkapannya di alam agar tidak merusak lingkungan karang.

Berdasarkan uraian tersebut di atas, perlu adanya dilakukan penelitian untuk mengetahui pengaruh padat tebar yang berbeda terhadap kelangsungan hidup dan pertumbuhan $B C F$ ( $P$. kaurdeni) pada wadah terkontrol. Selanjutnya, dilakukan penelitian pengaruh padat tebar yang berbeda terhadap kelangsungan hidup dan pertumbuhan $B C F$ (P. kaurdeni) pada wadah terkontrol.

\section{Metode Penelitian}

Penelitian ini dilaksanakan pada Bulan April hinggai Mei 2018, bertempat di Balai Perikanan Budidaya Laut Lombok Sekotong. Kabupaten Lombok Barat, Provinsi NTB.

Penelitian menggunakan Rancangan Acak Lengkap (RAL) dengan 3 perlakuan kepadatan yaitu perlakuan A $(0,833$ ekor/l), perlakuan B (1,667 ekor/l), dan C (2,5 ekor/l). dan 4 ulangan. Sebanyak 12 akuarium yang berukuran 40x30x50cm diisi air laut sebanyak $24 \mathrm{~L}$. Air laut yang digunakan diperoleh dari perairan wilayah Sekotong, Lombok Barat. Sebelum dimasukkan ke akuarium, air laut disaring menggunakan filter berupa karbon aktif, spons, dan pasir agar kualitas air laut yang digunakan tetap terjaga. Masing-masing akuarium diberikan aerasi menggunakan aerator yang berupa selang dan batu aerasi untuk mensuplasi oksigen di dalam wadah pemeliharaan. Pergantian air dilakukan setiap dua hari sekali yaitu pada pukul 08.00 wita sebanyak $30 \%$ atau penambahan air baru per dua hari sekali setiap unit percobaan.

Ikan $B C F$ yang digunakan yaitu ikan yang didapatkan dari hasil budidaya BBPBL Sekotong, Lombok Barat berukuran 2,5 cm $3,5 \mathrm{~cm}$. Setiap unit akuarium dimasukkan ikan $B C F$ sesuai dengan perlakuan yang diuji. Sebelum dimasukkan ke aquarium, ikan BCF diaklimatisasi dengan cara memasukkan ikan ke dalam baskom dan dibiarkan baskom tersebut melayang di permukaan wadah akuarium pemeliharaan ikan $B C F$ yang baru.

Pengukuran berat dan panjang ikan $B C F$ dilakukan pada hari ke-1, ke-10, ke-20 dan ke30. Berat diukur dengan timbangan analitik dengan ketelitian 0,01 gr. Pengukuran panjang Ikan $B C F$ dilakukan dengan menggunakan penggaris yang sudah dimodifikasi untuk berfungsi seperti jangka sorong. Pengukuran berat dan panjang dilakukan dengan cara pengambilan sampel ikan $B C F$ sebanyak 10 ikan $B C F$.

Selama masa pemeliharaan, ikan $B C F$ diberikan pakan berupa ikan rucah. Pemberian pakan dilakukan secara perhitungan 5\% dari berat tubuh ikan $B C F$. Pakan diberikan pada pukul 08:00 WITA dan 16:00 WITA. Sebelum pakan diberikan kepada ikan, pakan harus dibersihkan terlebih dahulu dan diambil dagingnya saja untuk dihaluskan mengggunakan blender. Kemudian pakan diberikan secara merata dengan cara di larutan 
menggunakan air terlebih dahulu. Perhitungan jumlah pemberian pakan dilakukan dengan cara penimbangan bobot ikan $B C F$ setiap 10 hari sekali dan hasilnya dikalikan 5\%, dinyatakan menurut Safrudin (2003) dengan rumus TPP $=5 \%$ x Jumlah bobot ikan (TPP : Jumlah pemberian pakan)

Pengukuran kualitas air dilakukan setiap tujuh hari sekali yang dilakukan pada pagi hari sebelum ikan diberikan pakan. Kualitas air yang diukur yaitu DO, pH, salinitas, dan suhu. Alat yang digunakan untuk mengukur suhu menggunakan alat Thermometer, $\mathrm{pH}$ diukur dengan alat $\mathrm{pH}$ meter, $\mathrm{DO}$ diukur dengan alat DO meter, sedangkan pengukur salinitas dilakukan menggunakan alat ukur Refraktometer. Pengukuran dilakukan dengan cara pengambilan sampel media pemeliharaan pada setiap akuarium menggunakan botol film.

Pengamatan kualiatas air akuarium di setiap unit penelitian dilakukan setiap tujuh hari sekali. Parameter yang diamati yaitu salinitas menggunakan refraktometer, DO menggunakan DO meter, pH menggunakan $\mathrm{pH}$ meter, dan suhu menggunakan thermometer. Setiap dilakukan pengamatan hasilnya dicatat hingga pengamatan di akhir penelitian agar diketahui kisaran dari media pemeliharaan $B C F$.

\section{Analisis Data}

Menurut Effendi (2002), perhitungan petumbuhan berat mutlak Banggai Cardinal Fish dirumuskan $\mathrm{W}=\mathrm{Wt}-\mathrm{Wo} \quad(\mathrm{W}=$ pertambahan berat $(\mathrm{gr}) ; \mathrm{Wt}=$ berat akhir; $\mathrm{Wo}=$ berat awal). Pertumbuhan panjang mutlak dihitung dengan rumus $\mathrm{Pm}=\mathrm{L}_{\mathrm{t}}-\mathrm{L}_{0}(\mathrm{Pm}=$ panjang mutlak $(\mathrm{cm}) ; \mathrm{Lt}=$ panjang rata-rata akhir (cm); $\mathrm{L}_{0}=$ panjang rata-rata awal.

Nilai laju pertumbuhan bobot harian dihitung dengan rumus (Jaya et al., 2015), sebagai berikut $\mathrm{LPH}=\mathrm{Lt}-\mathrm{L} 0 / \mathrm{hx} 100 \% \quad(\mathrm{LPH}=$ Laju pertumbuhan bobot harian (\%/hari) ; $\mathrm{Lt}=$ Panjang rata-rata pada akhir pemeliharaan $(\mathrm{cm}) ; \mathrm{L}_{0}=$ Panjang rata-rata pada awal pemeliharaan $(\mathrm{cm}) ; \mathrm{h}=$ Lama pemeliharaan (hari)). Tingkat kelangsungan hidup dapat diketahui dengan rumus $\mathrm{SR}=\mathrm{Nt} / \mathrm{N} 0 \times 100 \%$ ( $\mathrm{SR}=$ tingkat kelangsungan hidup; $\mathrm{Nt}=$ jumlah ikan yang hidup diakhir; $\mathrm{N}_{0}=$ jumlah ikan yang hidup diawal).

Untuk mengetahui pengaruh padat tebar yang berbeda terhadap kelangsungan hidup dan pertumbuhan Banggai Cardinal Fish, data pertumbuhan yang diperoleh dari hasil penelitian dianalisis menggunakan analisis sidik ragam (ANOVA) pada taraf nyata $5 \%$. Apabila hasil penelitian menunjukan perbedaan signifikan maka dilanjutkan dengan analisis beda nyata jujur (BNJ) pada taraf yang sama.

\section{Hasil}

\section{Panjang Mutlak Ikan $B C F$}

Penelitian padat tebar yang berbeda pada Ikan $B C F$ menunjukkan hasil yang tidak signifikan $(p>0,05)$ terhadap panjang mutlak. Akan tetapi, Gambar 1. memperlihatkan bahwa perlakuan B dengan jumlah padat tebar 1,667 ekor/l sebesar $0,737 \mathrm{~cm}$ ikan $B C F$ cenderung lebih tinggi pertumbuhan panjang mutlaknya kemudian disusul oleh perlakuan C dan perlakuan A yang mengalami peningkatan panjang mutlak pada ikan $B C F$ yang dipelihara.

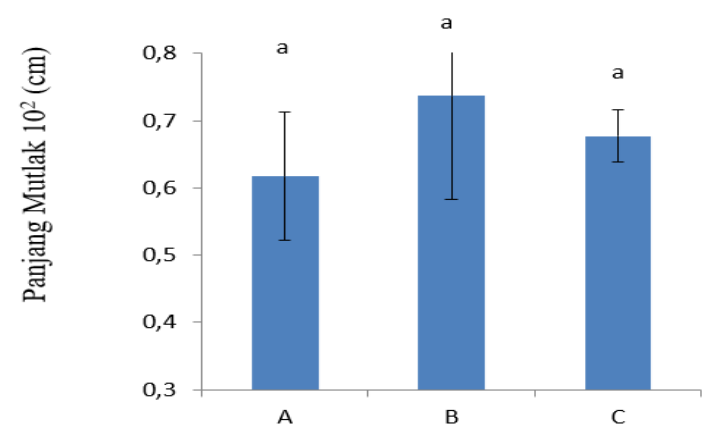

Gambar 1. Pertumbuhan panjang mutlak ikan $B C F$ yang diberikan perlakuan A dengan kepadatan 0,833 ekor/l, perlakuan B dengan kepadatan 1,667 ekor/l, dan perlakuan C dengan kepadatan 2,5 ekor/l.

\section{Berat Mutlak Ikan $B C F$}

Ikan $B C F$ yang diberikan perlakuan pada tebar berbeda menunjukkan hasil yang tidak signifkan $(p>0,05)$ terhadap berat mutlak. Namun, pertumbuhan berat cenderung lebih tinggi pada perlakuan $\mathrm{B}$ dengan padat tebar 1,667 ekor/l sebesar 0,325 g kemudian disusul perlakuan A dan perlakuan C. Hasil pertumbuhan berat mutlak dapat dilihat pada Gambar. 2.

\section{Hubungan Antara Panjang dan Berat Mutlak Ikan $B C F$}

Penelitian pengaruh padat tebar yang berbeda pada pertumbuhan ikan $B C F$ dapat diketahui, adanya hubungan antara panjang mutlak dan berat mutlak sari ikan $B C F$. 
Hubungan antara keduanya dapat dilihat pada Tabel 1, adanya nilai persamaan yang berbeda pada setiap perlakuan. Namun, setiap perlakuan memiliki nilai $\mathrm{b}<3$, yang dapat dikatakan bahwa hubungan panjang berat bersifat allometrik negatif.

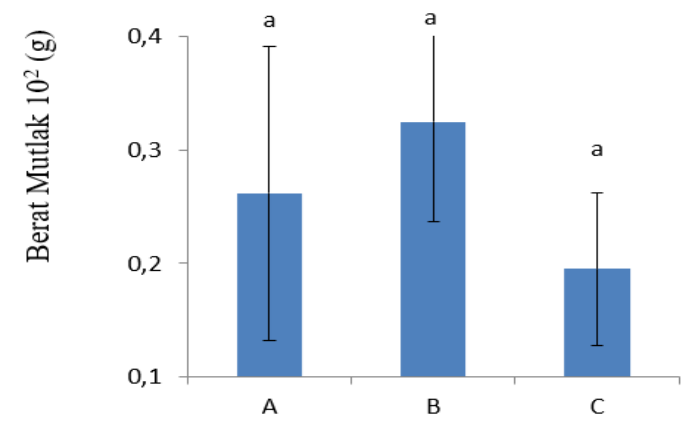

Gambar 2. Pertumbuhan berat mutlak ikan $B C F$ yang diberikan perlakuan $\mathrm{A}$ dengan kepadatan 0,833 ekor/l, perlakuan B dengan kepadatan 1,667 ekor/l, dan perlakuan C dengan kepadatan 2,5 ekor/l.

Tabel 1. Hubungan panjang dan berat ikan $B C F$ dengan nilai a adalah intercept dan nilai $b$ adalah konstanta

\begin{tabular}{llll}
\hline \multirow{2}{*}{ Parameter } & \multicolumn{3}{c}{ Kepadatan } \\
\cline { 2 - 4 } & 0,833 ekor/l & 1,677 ekor/l & 2,5 ekor/l \\
\hline $\begin{array}{l}\text { Panjang } \\
\text { Mutlak (cm) }{ }^{\mathrm{ns}}\end{array}$ & $0.617 \pm 0.0$ & $0.737 . \pm 0.1$ & $0.677 \pm 0.0$ \\
$\begin{array}{l}\text { Bobot } \\
\text { Mutlak (g) }{ }^{\mathrm{ns}}\end{array}$ & $0.262 \pm 0.1$ & $0.325 \pm 0.0$ & $0.195 \pm 0.0$ \\
LPH (\%) & $0.608 \pm 0.0^{\mathrm{a}}$ & $0.689 \pm 0.0^{\mathrm{b}}$ & $0.614 \pm 0.0^{\mathrm{a}}$ \\
SR (\%) & $80.0 \pm 14.7^{\mathrm{b}}$ & $78.1 \pm 3.7^{\mathrm{ab}}$ & $54.5 \pm 14.0^{\mathrm{a}}$ \\
\hline
\end{tabular}

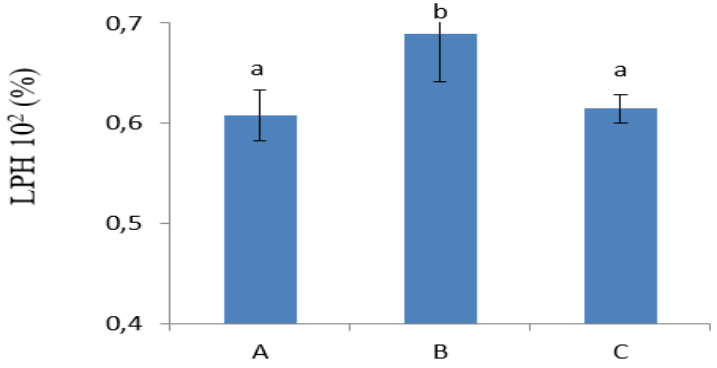

Gambar 3. Laju pertumbuhan berat harian (LPH) ikan $B C F$ yang diberikan perlakuan A dengan kepadatan 0,833 ekor/l, perlakuan B dengan kepadatan 1,667 ekor/l, dan perlakuan $\mathrm{C}$ dengan kepadatan 2,5 ekor/l.

\section{Tingkat Kelangsungan Hidup (SR) Ikan BCF}

Berdasarkan jumlah individu yang hidup selama masa pemeliharaan, tingkat kelangsungan hidup (SR) pada ikan $B C F$ menunjukkan hasil yang signifikan $(\mathrm{p}<0,05)$. Diketahui, bahwa adanya pengaruh SR terhadap perlakuan padat tebar yang diberikan. Tingkat kelangsungan hidup ikan $B C F$ paling tinggi pada perlakuan A dengan padat tebar 0,833 ekor/l yaitu sebesar $80 \%$, selanjutnya perlakuan B dengan padat tebar 1,667 ekor/l yaitu sebesar $78.125 \%$ dan terendah pada perlakuan $\mathrm{C}$ dengan padat tebar 2,5 ekor/l yaitu sebesar 54.583\%. Grafik tingkat kelangsungan hidup (SR)

\section{Laju Pertumbuhan Berat Harian Ikan BCF}

Laju pertumbuhan berat harian (LPH) pada ikan $B C F$ selama masa penelitian menunjukkan adanya perbedaan yang nyata $(\mathrm{p}<0,05)$. Hasil uji lanjut menggunakan Tukey (HSD) memeperlihatkan bahwa, pada perlakuan B dengan padat tebar 1,667 ekor/l menunjukkan adanya peningkatan LPH yang sangat tinggi yaitu sebesar $0,689 \%$. Selanjutnya disusul oleh perlakuan $\mathrm{C}$ dengan padat tebar 2,5 ekor/l yaitu sebesar $0,614 \%$ dan peningkatan terendah pada perlakuan A dengan padat tebar 0,833 ekor/l yaitu sebesar $0,608 \%$. Hasil tersebut dapat dilihat pada Gambar 3. dapat dilihat pada Gambar 4.

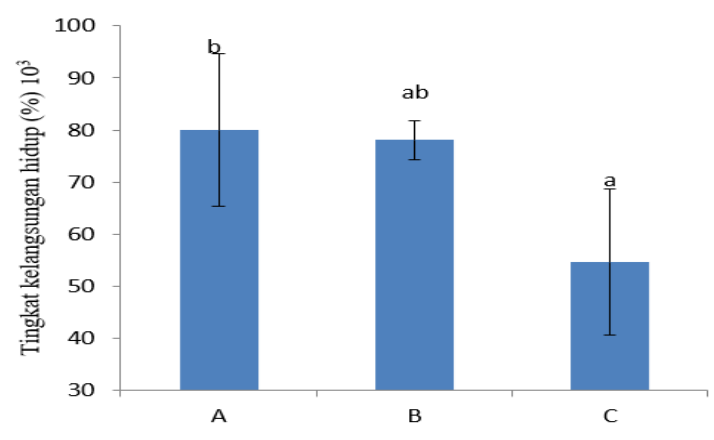

Gambar 4. Tingkat kelangsungan hidup (SR) ikan $B C F$ yang diberikan perlakuan A dengan kepadatan 0,833 ekor/l, perlakuan B dengan kepadatan 1,667 ekor/l, dan perlakuan $\mathrm{C}$ dengan kepadatan 2,5 ekor/l. 


\section{Kualitas Air Ikan $B C F$}

Pengukuran kualitas air dilakukan setiap minggunya selama masa pemeliharaan. Parameter yang diukur adalah suhu $\left({ }^{0} \mathrm{C}\right)$, Oksigen Terlarut (DO) (mg/l), $\mathrm{pH}$, dan salinitas (ppt). Hasil pengukuran parameter kualitas air ikan $B C F$ yang dilakukan selama pemeliharaan 30 hari diperoleh hasil nilai kisaran dapat dilihat pada Tabel 2.

Tabel 2. Kualitas air ikan $B C F$ selama masa pemeliharaan

\begin{tabular}{llll}
\hline $\begin{array}{l}\text { Para- } \\
\text { meter }\end{array}$ & Satuan & Hasil & Sumber Pustaka \\
\hline Suhu & ${ }^{0} \mathrm{C}$ & $28,65 \pm 0,86$ & $\begin{array}{l}28-33^{\circ} \mathrm{C} \\
\text { (Vagelli, 2005) }\end{array}$ \\
$\mathrm{DO}$ & $\mathrm{Mg} / \mathrm{l}$ & $5,34 \pm 0,22$ & $\begin{array}{l}4,3-5,8, \mathrm{mg} / \mathrm{l} \\
(\text { Sugama, 2008) }\end{array}$ \\
$\mathrm{pH}$ & - & $8,10 \pm 0,17$ & $\begin{array}{l}8,1-8,4 \text { (Carlos, } \\
2014)\end{array}$ \\
$\begin{array}{l}\text { Salini- } \\
\text { tas }\end{array}$ & Ppt & $33,50 \pm 0,50$ & $\begin{array}{l}32,8-34,1 \mathrm{ppt} \\
(\text { Sugama, 2008) }\end{array}$ \\
\hline
\end{tabular}

\section{Pembahasan}

\section{Pertumbuhan Ikan $B C F$}

Pertumbuhan merupakan perubahan ukuran, baik panjang maupun berat tubuh dalam suatu periode atau waktu tertentu (Effendi, 2002). Penelitian panjang mutlak pada ikan $B C F$ yang diperoleh tidak berbeda nyata $(p>0,05)$. Hal ini dapat disimpulkan, bahwa kepadataan yang berbeda dalam setiap perlakuan yang diberikan tidak menunjukkan adanya perbedaan yang nyata pada pertumbuhan panjang mutlak dari ikan $B C F$. Namun, pertumbuhan ikan $B C F$ yang dipelihara selama 30 hari dengan kepadatan 1,667 ekor/l sebesar $0,737 \mathrm{~cm}$ memiliki panjang mutlak lebih besar dibandingkan dengan pertumbuhan ikan $B C F$ di alam. Menurut Saraswati (2014), ikan $B C F$ dapat mencapai panjang sebesar $0,292 \mathrm{~cm}-0,389$ $\mathrm{cm}$ dalam kurun waktu 30 hari.

Ikan $B C F$ dapat dikatakan sebagai ikan yang pertumbuhan panjangnya lambat. Menurut Convention On International Trade In Endangered Species Of Wild Fauna And Flora (2017), Pterapogon kaurdeni adalah ikan laut kecil (ukuran maksimum $80 \mathrm{~mm}$ (SL)) dengan ciri khas pola kontras hitam dena terang dengan bintik-bintik putih. Menurut Nodbe et al. (2013), ikan Banggai Cardinal adalah ikan kecil dengan panjang standar maksimum sekitar $6 \mathrm{~cm}$ dari family Apogonidae.
Pertumbuhan berat mutlak ikan $B C F$ memperlihatkan hasil yang tidak berbeda nyata $(p>0,05)$. Namun demekian, terlihat pada Gambar 2. pertumbuhan ikan $B C F$ pada kepadatan 1,667 ekor/l cenderung lebih tinggi dibandingkan perlakuan lainnya. Pertumbuhan berat mutlak ikan $B C F$ selama masa pemeliharaan 30 hari ini menunjukkan berat mutlak lebih rendah dibandingkan dengan pertumbuhan berat mutlak ikan nemo yang satu family dengan ikan $B C F$. Pertumbuhan berat mutlak ikan $B C F$ hanya sebesar 0,326 gram atau setengah dari berat mutlak ikan nemo. Menurut Arjanggi (2013), ikan nemo memiliki pertumbuhan berat mutlak sebesar 0,75 gram $/ 30$ hari.

Berdasarkan hubungan panjang berat, ikan $B C F$ memiliki sifat allometrik negatif. Hal ini terlihat pada nilai kostanta b lebih kecil dari tiga (Tabel 1.) pada setiap perlakuan. Namun, pada kepadatan 1,667 ekor/l memiliki nilai konstanta lebih kecil (0,392) dibandingkan kepadatan yang lainnya. Hal ini menunjukkan bahwa pertumbuhan panjang ikan $B C F$ pada kepadatan 1,667 ekor/l memiliki kecepatan 0,3 kali lebih cepat pertumbuhan panjangnya daripada perlakuan lainnya. Pernyataan ini didukung oleh Sunarto et al. (2010), yang menyatakan jika $b<3$ menunjukkan kecepatan pertambahan panjang lebih cepat dibandingkan pertambahan berat sedangkan jika b>3 berarti kecepatan pertambahan berat lebih tinggi dibandingkan pertambahan panjang.

Laju pertumbuhan berat harian (LPH) menunjukkan adanya hasil yang berbeda nyata $(\mathrm{p}<0,05)$ antar perlakuan. Hasil peningkatan laju pertumbuhan berat harian terlihat pada Gambar 3. Dengan demikian, laju pertumbuhan berat harian ikan $B C F$ selama masa pemeliharaan mengalami peningkatan setiap harinya. Peningkatan LPH tertinggi pada kepadatan 1,667 ekor/l sebesar 0,689\%. Hal ini diduga karena ikan $B C F$ telah mampu beradaptasi dengan lingkungan dan volume air pada wadah pemeliharaan, dimana pada kepadatan 1,667 ekor/l ikan $B C F$ terlihat aktif dan mampu memanfaatkan pakan yang diberikan dengan baik. Hal ini diperkuat oleh pendapat Sugama (2008) yang menyatakan bahwa, ikan $B C F$ dapat diadaptasikan pada akuarium dengan kepadatan 2 ekor/l. 


\section{Tingkat Kelangsungan Hidup (SR) Ikan BCF}

Kelangsungan hidup (SR) merupakan persentase jumlah total ikan yang hidup pada akhir pemeliharaan dari jumlah total ikan pada awal pemeliharaan. Gambar 4. memperlihatkan bahwa tingkat kelangsungan hidup setiap perlakuan memiiki nilai yang berbeda. Tingkat kelangsungan hidup tertinggi terdapat pada kepadatan 0,833 ekor/l dan 1,667 ekor/l yaitu sebesar $80 \%$ dan $78 \%$, kemudian terendah pada kepadatan 2,5 ekor/l sebesar 54,583\%. Tingginya tingkat kelangsungan hidup pada kepadatan 0,833 ekor/l disebabkan karena tercukupinya ruang gerak dalam wadah pemeliharaannya. Hal ini sesuai dengan pendapat Gustriana (2008), yang mengatakan bahwa tingkat kelangsung hidup ikan dipengaruhi oleh faktor internal dan eksternal. Faktor internal meliputi: keturunan, umur, ketahanan terhadap penyakit, dan kemampuan memanfaatkan makanan, sedangkan faktor eksternal meliputi kualitas air dan ruang gerak.

Selama 30 hari masa pemeliharaan ikan $B C F$ dengan kepadatan yang berbeda, tidak mempengaruhi pertumbuhan ikan $B C F$ baik panjang mutlak maupun berat mutlak. Diduga karena waktu pemeliharaan ikan $B C F$ yang sangat terbatas, sehingga perlakuan yang diberikan tidak mempengaruhi pertumbuhan panjang mutlak dan berat mutlak ikan $B C F$. Akan tetapi, padat tebar yang berbeda memberikan pengaruh terhadap kelangsungan hidup dan laju pertunbuhan berat harian ikan $B C F$. Hal ini diduga bahwa semakin rendah kepadatan maka semakin tinggi tingkat kelangsung hidup (Gambar 4.). Hal ini sesuai dengan pendapat Rahmat (2010), bahwa kepadatan yang tinggi menyebabkan ikan akan bersaing dalam memanfaatkan ruang gerak, sehingga mempengaruhi tingkat kelangsungan hidup dan laju pertumbuhan ikan.

\section{Kualitas Air}

Berdasarkan data hasil pengamatan kualitas air, diperoleh nilai suhu berkisar antara $26^{\circ} \mathrm{C}-29^{\circ} \mathrm{C}$. Kondisi tersebut masih dalam kisaran optimal sesuai dengan kondisi suhu pada habitat alami Banggai Cardinal Fish, sehingga kondisi tersebut layak untuk dilakukan kegiatan budidaya. Hal ini sesuai dengan pernyataan Yulfiperius (2011) yang menyatakan bahwa, ikan Banggai Cardinal Fish dapat ditemukan pada perairan laut dangkal pada kedalaman 0-5 m dengan suhu 26-28 ${ }^{\circ}$. Menurut Azwa et al. (2016), suhu berpengaruh langsung pada laju proses fisiologis ikan yaitu derajat metabolisme dan siklus reproduksi, yang selanjutnya berpengaruh terhadap cara makan dan pertumbuhannya. Selain itu, pengaruh suhu terhadap ikan adalah dalam proses metabolisme, seperti pertumbuhan dan pengambilan makanan, aktivitas tubuh seperti, kecepatan renang serta dalam rangsangan saraf.

Pengukuran oksigen terlarut pada media pemeliharaan diperoleh kisaran antara 4,3-5,5 mg/l. Kisaran tersebut masih mampu ditoleransi oleh ikan $B C F$. Hal ini sesuai dengan pernyataan Gunawan (2011), oksigen terlarut yang mampu ditoleransi ikan $B C F$ berkisar antara 5,4-6,1 mg/L

Menurut Gunawan et al. (2011), habitat alami Banggai Cardinal Fish ditemukan pada perairan laut dangkal dengan $\mathrm{pH} 8,2-8,5$. Hal ini membuktikan bahwa kisaran $\mathrm{pH}$ pada akuarium pemeliharaan Banggai Cardinal Fish masih dalam kisaran yang optimum yaitu 7,78,3 dan layak untuk dilakukan kegiatan budidaya.

Hasil pengamatan salinitas selama pemeliharan didapatkan kisaran 33-35 ppt. Hal ini sesuai dengan pendapat Carlos et al. (2014), menyatakan bahwa kisaran salinitas habitat alami Banggai Cardinal Fish yaitu 3334 ppt. Selain itu, salinitas dan $\mathrm{pH}$ memiliki keterkaitan, apabila suatu perairan memiliki salinitas tinggi maka akan diikuti dengan nilai pH yang tinggi. Menurut Yulan et al. (2013), semakin tinggi suhu maka salinitas akan meningkat. Sementara itu, hal tersebut dapat mempengaruhi osmerogulasi pada ikan, dan pertumbuhan ikan.

\section{Kesimpulan}

Berdasarkan hasil penelitian pengaruh padat tebar yang berbeda terhadap tingkat kelangsungan hidup dan pertumbuhan ikan Banggai Cardinal Fish dapat ditarik kesimpulan sebagai berikut:

- Tingkat kelangsungan hidup tertinggi ikan $B C F$ terdapat pada kepadatan 0,833 ekor/l dan 1,667 ekor/l sebesar $80 \%$ dan $78 \%$

- Laju Pertumbuhan Berat Harian (LPH) tertinggi terdapat pada kepadatan 1,667 ekor/l sebesar $0,689 \%$ 


\section{Daftar Pustaka}

Arjanggi, M., Isnaini \& Melki (2013). Laju Pertumbuhan dan Kelangsungan Hidup Benih Clownfish (Amphriprion ocellaris) dengan Pakan Pellet Berbeda (Love larva, $N R D$, dan TetraBits) Skala Laboratorium. Maspari Journal. Volume 5 (1), Halaman 50-55.

Azwar M., Emiyarti \& Yusnaini (2016). Crtical Thermal dari Ikan Zebrasoma scope yang Berasal dari Perairan Pulau Hoga Perairan Wakatobi. Sapa Laut. Volume 1 (2) : 60-66.

Carlos, N.S.T., A. B. Rondonuwu \& V.N.R. Watung (2014) . Distribusi dan Kelimpahan Pterapogon kauderni Koumnas, 1933 (Apogonidae) di selat Lembah Bagian Timur, Kota Bitung. Jurnal Ilmiah Platax. Vol. 2 (3).

Diatin, I., E. Harris. M. A. Suprayudi \& T. Budiardi (2014). Pertumbuhan dan Kelangsungan Hidup Ikan Hias Koridoras (Corydoras aenus Gill 1885) Pada Budidaya Kepadatan Tinggi. Jurnal Ikhtiologi Indonsia. Volume 14 (2) :123134.

Effendie, I. I. (2002) . Biologi Perikanan. Yogyakarta : Yayaysan Pustaka Nusantara.

Gunawan., J. H. Hutapea \& K. M. Setiawati (2010) . Pemeliharaan Induk Capungan Banggai (Pterapogon kauderni) Dengan Kepadatan Yang Berbeda. Prosiding Forum Inovasi Teknologi Akuakultur. 461466.

Gustriana. (2008). Budidaya Ikan Jilid 1 SMK. Departemen Pendidikan Nasional. Indonesia. Indonesia.

Ndobe, S. (2011) . Pertumbuhan Ikan Hias Banggai Cardinalfish (Pterapogon kauderni) Pada Media Pemeliharaan Salinitas Yang Berbeda. Media Litbang Sulteng. IV(1), 52-56.

Ndobe, S., A. Moore, A. I. M. Salanggon, Muslihudin, D. Setyohadi, E. Y. Herawati, \& Soemarno. (2013). Pengelolaan Banggai Cardinal Fish (Pterapogon kaurdeni) Melalui Konsep Ecosystem-Based Approach. Marine Fisheries. Volume 4, No. 2. Halaman 115-126.

Rahmat. (2010). http;//kepadatan ikan. 12 Oktober 2012.

Saraswati, N. L. G. A. R. (2014). Konservasi Ikan Banggai Kardinal Di Perairan Kepulauan Banggai Sulawesi Tengah. Skripsi. Fakultas Kelautan Dan Perikanan, Universitas Udayana. Bali.

Sugama, K. (2008). Pemijahan dan Pembesaran Anak Ikan Kardinal Banggai (Pterapogon kaurderni). Pusat Riset Perikanan Budidaya Jakarta. Volume 3 (1), 83-90.

Vagelli, A.A. (2008). The Unfortunate Journey Of Pterapogon Kauderni : A Remakable Apogonid Endangered by the International Ornamental Fish Trade, and Its Case in CITES. SPC Live Reef Information Bulletin. 18, 7-28.

Yulan, A., I. A. Anrosana, \& A. A. Gemaputri (2013). Tingkat Kelangsungan Hidup Benih Ikan Nila Gift (Oreochromis niloticus) pada Salinitas yang Berbeda. Jurnal Perikanan (J. Fish Sci.). XV (2): 78-82.

Yulfiperius. (2011) . Banggai Cardinal Fish (BCF) Ikan Hias Asli Indonesia. Diterbitkan di Majalah Triwulan UniL. Retrieved from: http://yulfiperius.file.wordpress.com/2011/ 07/banggaicardinalfiss. 